\title{
THE FUNERAL CEREMONY OF EARLY SARMATIAN CULTURE WITH THE ITEMS OF THE CARRIAGE IN THE TOP OF THE BURIAL CHAMBER (THE LOWER VOLGA REGION) ${ }^{1}$
}

\author{
Valeriy M. Klepikov \\ Volgograd State University, Volgograd, Russian Federation
}

\begin{abstract}
The Funeral Ceremony of Early Sarmatian archaeological culture is sufficiently described in the historical literature from the viewpoint of general standardizing signs. Currently, much more attention is paid to special elements, for example, the elements of carriages: wheels, hubs, parts of the bodywork, which were found in the entrance pit of the burial chamber. A small number of such complexes increase gradually, and in the Early Sarmatian period they were concentrated in the Lower Volga region as shown by the records from both sides of the river. We should point out the chronological certainty of the complexes which can be narrowly dated and date back to the $2^{\text {nd }}-1^{\text {st }} \mathrm{BC}$. Taking into account the Eastern migration impulse of this period, reflected in a whole series of Eastern-origin innovations in the territory of the Lower Volga region and the funerary traditions of Central Asia, it can be assumed that the emergence of the carriage's wheels over the burial's top is also associated with the emergence of a new population migrated from the East. A peculiar feature of the Funeral Ceremony is the intake burials being separate and not formed like a burial ground. We can assume that single burials had appeared during the period of the territory's development. It should be noted that in the $2^{\text {nd }}-1^{\text {st }}$ centuries $\mathrm{BC}$ in the Lower Volga region there were signs of burials in the Northern sector in contrast to the traditional South, in decks with plenty of fishnet and jet buckles, long swords without metal pommel with Oriental origins. The list of innovations, of course, includes the appearance of the wheels in the top of the burial chamber.

Key words: Early Sarmatian archaeological culture, Lower Volga region, funeral ceremony, carriages, wheels, migrations.

Citation. Klepikov V.M. The Funeral Ceremony of Early Sarmatian Culture with the Items of the Carriage in the Top of the Burial Chamber (the Lower Volga Region). Vestnik Volgogradskogo gosudarstvennogo universiteta. Serija 4, Istorija. Regionovedenie. Mezhdunarodnye otnoshenija [Science Journal of Volgograd State University. History. Area Studies. International Relations], 2017, vol. 22, no. 3, pp. 20-35. (in Russian). - DOI: https://doi.org/ 10.15688/jvolsu4.2017.3.2.
\end{abstract}

\section{ПОГРЕБЕНИЯ РАННЕСАРМАТСКОЙ КУЛЬТУРЫ НИЖНЕГО ПОВОЛЖЬЯ С ДЕТАЛЯМИ ПОВОЗКИ В ЗАКЛАДЕ МОГИЛЬНОЙ КАМЕРЫ ${ }^{1}$}

\author{
Валерий Михайлович Клепиков \\ Волгоградский государственный университет, г. Волгоград, Российская Федерация
}

\footnotetext{
Аннотация. Погребальный обряд раннесарматской археологической культуры достаточно хорошо описан с позиции общих стандартизирующих признаков. В настоящее время гораздо больше внимания уделяется особенным элементам, среди которых неоднократно обращалось внимание на элементы повозок: колеса, ступицы, детали кузова, - находимые во входной яме погребальной камеры. Небольшое количество таких комплексов постепенноувеличивается, причем на раннесарматском этапе они концентрируются в Нижнем Поволжье, где фиксируются по обе стороны Волги. Обращает на себя внимание хронологическая определенность тех комплексов, которые могуг быть узко датированы. Все они не выходят за рамки II-I вв. до н.э. Учитывая известный восточный миграционный импульс этого периода, отразившийся в целом наборе инноваций явно восточного происхождения на территории Нижнего Поволжья, и погребальные традиции Центральной Азии, можно предположить, что появление заклада погребения колесами повозки также связано с появлением нового населения, мигрировавшего с востока.
} 
Ключевые слова: раннесарматская археологическая культура, Нижнее Поволжье, погребальный обряд, повозки, колеса, миграции.

Цитирование. Клепиков В. М. Погребения раннесарматской культуры Нижнего Поволжья с деталями повозки в закладе могильной камеры // Вестник Волгоградского государственного университета. Серия 4, История. Регионоведение. Международные отношения. - 2017. - Т. 22, № 3. - С. 20-35.-DOI: https://doi.org/10.15688/jvolsu4.2017.3.2.

В настоящее время типичные элементы погребального обряда раннесарматской археологической культуры выявлены достаточно полно, для того чтобы говорить о стандартизированных нормах, сложившихся в кочевых обществах Нижнего Поволжья и Южного Приуралья в общих хронологических границах IV-I вв. до н.э. и использовать этот стандарт как определенный погребальный эталон при изучении соответствующей этнокультурной группы. На этом фоне «всеобщего» весьма отчетливо проявляются «особые» элементы, рождающие новые вопросы к содержанию погребального обряда. Одной из таких черт, невписывающихся в традиционную совокупность элементов погребальной традиции ранних сарматов на указанной территории, можно назвать спорадически встречающуюся практику заклада входной ямы погребения колесами и отдельными деталями заранее разобранной или сломанной повозки. К настоящему времени насчитывается десять таких погребений в Нижнем Поволжье (см. рис. 1).

Впервые такие погребения были обнаружены и описаны И.В. Синицыным в 1929 г. при раскопках у с. Меркель (Макаровка) на реке Карамыш в 30-40 км к западу от Волги, где в прямоугольной яме на провалившемся перекрытии впускного погребения 3 кургана G2 были найдены три колеса со ступицами и четыре оси [8, c. 75-77]. В том же году в Заволжье были продолжены раскопки курганов у с. Усатово, где в кургане G5 в узкой прямоугольной яме погребения 2 в засыпи над костяком также была обнаружена ступица с остатками спиц [8, с. 91-92]. Интересно, что в погребении 5 этого же кургана уже в подбойном захоронении среди слоя лозы, сохранившейся от заклада, найдена еще одна ступица и спицы [8, с. 94-96]. Погребальный обряд и сопутствующий инвентарь явно свидетельствуют о раннесарматской погребальной традиции (см. рис. 2, 3).

В 50-Х гг. ХХ в. исследование курганов Волжского левобережья в зоне строительства Сталинградского водохранилища пополнило список погребений с остатками повозок двумя новыми находками. У с. Политотдельское во впускном погребении 19 кургана 12 (см. рис. 4) в узкой яме с заплечиками, опять же на перекрытии лежало колесо, сломанное на две части, поскольку диаметр около 1,2 м не позволял положить его на заплечики. Вместе с провалившимся в яму колесом лежали обломки кузова повозки [11, с. 268-272]. В могильнике Быково I также в яме с заплечиками в заполнении над костяком лежали деревянные детали повозки с обломками четырех колес (см. рис. 6). По непонятной причине это погребение было отнесено К.Ф. Смирновым к среднесарматскому времени, хотя сама традиция кургана-кладбища и сопутствующий материал не дают к этому никаких оснований [10, c. 220]. На это уже обращал внимание Ф.Р. Балонов в статье, посвященной повозкам сарматского времени [1, с. 80].

В дальнейшем погребения раннесарматского времени были обнаружены в группе Кривая Лука VIII на правом берегу Волги, где вновь в кургане-кладбище 5 во впускном центральном погребении 15 вдоль ступеньки были расчищены отпечатки ступиц четырех колес, положенных, очевидно, на край ступеньки и частично перекрывавших стенку гроба (см. рис. 9). Прямоугольная яма этого погребения с женщиной и ребенком, видимо, частично нарушила более раннее захоронение в подбое [13]. Не совсем понятно, почему в публикации Ф.Р. Балонова говорится о трех колесах (он даже предполагает сломанные два колеса) и неверно указана ориентировка погребенных женщины и подростка, которые по тексту отчета были ориентированы головой к ЮВ, а не к С3 [1, с. 76-77].

В 80-90-Х гг. XX в. серия погребений с повозками вновь пополнилась. В Астраханской области у с. Косика в 1984 г. были раскопано впущенное в бэровский бугор женское подбойное погребение 2 с богатым инвентарем и двумя колесами, закрывавшими вход в камеру (см. рис. 10) [7, с. 170].

Археологическая экспедиция Куйбышевского педагогического института в 1989 г. 
вновь у с. Политотдельское раскопала курган 4, где в центре было обнаружено погребение 13 , представлявшее собой могильную яму с двумя подбоями в восточной и западной сторонах. Обе камеры были закрыты колесами, западная - тремя, восточная - двумя. Погребенные сопровождались мечами и глиняными сосудами. В одном найдены фрагменты среднелатенской фибулы с подвязной ножкой и бронзовая пряжка (см. рис. 5) [2].

В процессе охранных раскопок экспедиция Волгоградского государственного университета в 1991 г. у х. Антонов в Волго-Донском междуречье обнаружила погребение 3 в кургане 3 , где в могильной яме с заплечиками над погребенным с двумя мечами найдены детали повозки и прослежены два колеса на уровне заплечиков (см. рис. 8) [4, с. 22-26].

И наконец в том же году археологи Волгоградского педагогического университета в Заволжье у с. Солодовка исследовали погребение 9 кургана 4, в котором подбойная камера была закрыта закладом из дощечек и деревянным колесом, от которого, как и от заклада, сохранились только отпечатки в грунте. Погребенный лежал в колоде с традиционным прохоровским мечом, оселком и обломком зеркала с валиком по краю (см. рис. 7) [6].

Следует отметить, что во всех случаях повозка перед погребением либо разбиралась, либо сознательно ломалась и, видимо, для соблюдения обрядовых норм не требовалось укладки всех деталей в могильную яму. Часть символизировала целое. Об этом же говорит и тот факт, что количество колес неодинаково и варьирует от одного до четыpex. Колеса либо ставились в яму вертикально, закрывая подбой, либо укладывались на заплечики горизонтально. Следует заметить, что появление такого обычая не имеет параллелей в погребальном обряде соседних территорий. Единственным примером может быть лишь погребение 1 кургана 1 у с. Любимовка в местности Лапасина по р. Бузулук, датируемое IV в. до н.э. (см. рис. 11) $[12$, с. 90 , рис. 33]. Все аналогии связаны с более восточными районами, включая колесницы и модели повозок эпохи Хань, повозки сюнну, Пазырыка, что неоднократно отмечалось в литературе [7, с. 172]. Могильные ямы представлены двумя типами: либо неширо- кие прямоугольные, зачастую с заплечиками, либо подбойные, включая вариант с двумя подбоями с разных сторон входной ямы. Во всех погребениях есть гробы, в одном случае даже колода, но в основном гробовые конструкции представлены решетчатым вариантом, что в сарматских погребениях не редкость. Еще одна особенность погребального обряда - впускные погребения нередко одиночны в кургане, то есть вокруг них не формировались курганы-кладбища. Поскольку есть и противоположные примеры, возможно, следует предположить, что одиночные погребения сооружались на стадии освоения территории. Эту же мысль высказал и Б.А. Раев [7, с. 171].

Хронология тех комплексов, которые позволяют уточнить дату погребений, не выходит за рамки II-I вв. до н.э. Фрагментированная среднелатенская фибула с подвязной ножкой из Политотдельского (см. рис. 5,8 ), видимо, может быть датирована в пределах I в. до н.э. [3, с. 48-49]. Угвентарий веретенообразной формы на ножке с выраженными плечиками из Политотдельского (рис. 4) также может быть датирован серединой II - серединой I в. до н.э. [5, с. 42]. Сероглиняная керамика из Политотдельского (кург. 12 погр. 19), Антонова (кург. 3 погр. 3), Косики (погр. 2) тоже бытует в этих границах [9, рис. 5].

Анализ погребального обряда комплексов раннесарматской культуры Нижнего Поволжья с повозками позволяет в очередной раз констатировать, что при сохранении стандартных традиций погребальной обрядности на протяжении всего периода во II-I вв. до н.э. явно прослеживаются восточные инновации. Мы неоднократно отмечали появление в это время северной ориентировки, совершение захоронений в колодах, распространение ажурных и гагатовых пряжек, длинных мечей без металлического навершия, имеющих восточные истоки [9, с. 99-100]. В список таких инноваций безусловно входит и появление колес в закладе могильной камеры.

\section{ПРИМЕЧАНИЕ}

${ }^{1}$ Статья выполнена в рамках Государственного задания Минобрнауки РФ, проект № 33.2830.2017/4.6 «Юг России в эпоху раннего железного века: диалог культур Восток - Запад». 


\section{ПРИЛОЖЕНИЯ}

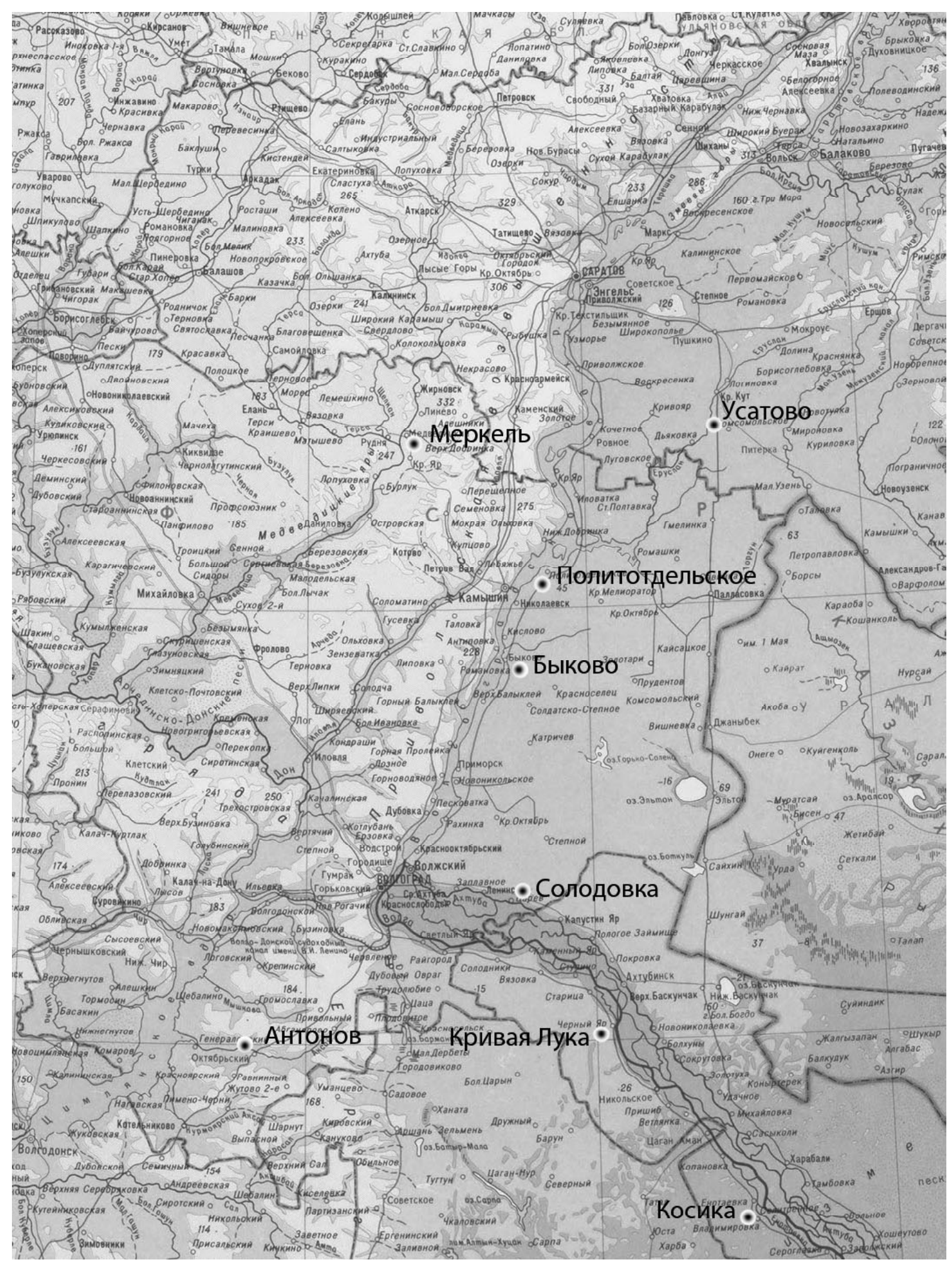

Рис. 1. Территория распространения раннесарматских погребений с повозками в Нижнем Поволжье

Fig. 1. Territory of Early Sarmatian burials with carts in the Lower Volga region 

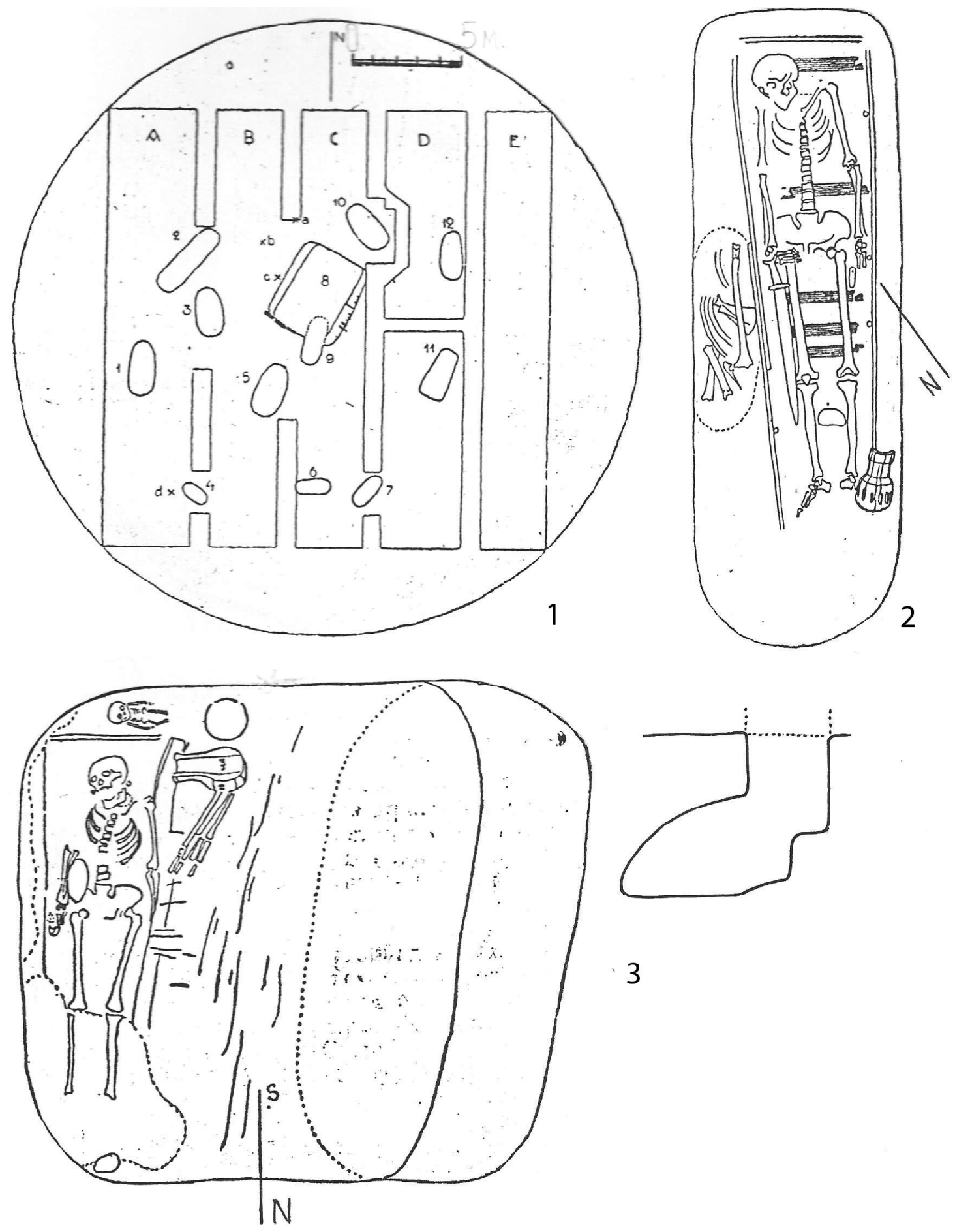

Рис. 2. Усатово, курган G 5, погребения 2 и 5:

1 - план кургана; 2 - погребение 2 ; 3 - погребение 5

Fig. 2. Usatovo, barrow $\mathrm{G} 5$, burials 2 and 5:

1 - plan of the barrow; 2 - burial 2; 3 - burial 5 


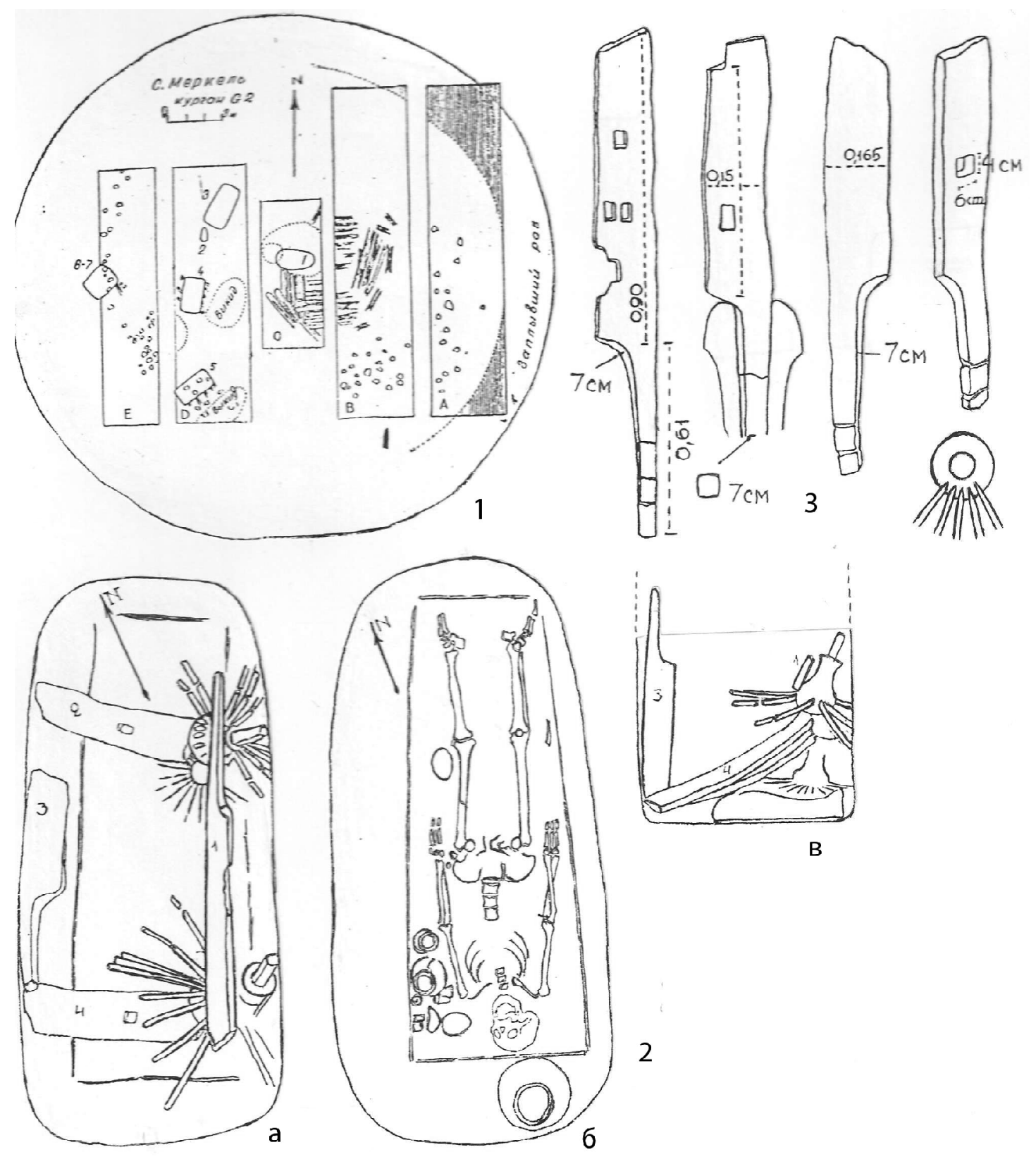

Рис. 3. Меркель, курган G 2, погребение 3:

1 - план кургана; 2 - погребение 3 ( $a$ - заклад; 6 - погребение; 8 - заклад, вид сбоку); 3 - формы и размеры осей повозки

Fig. 3. Merkel, barrow G 2, burial 3:

1 - plan of the barrow; 2 - burial 3 ( $a$ - backfill; $b$ - burial; $c$ - backfill, profile view); 3 - forms and size of cart's axes 

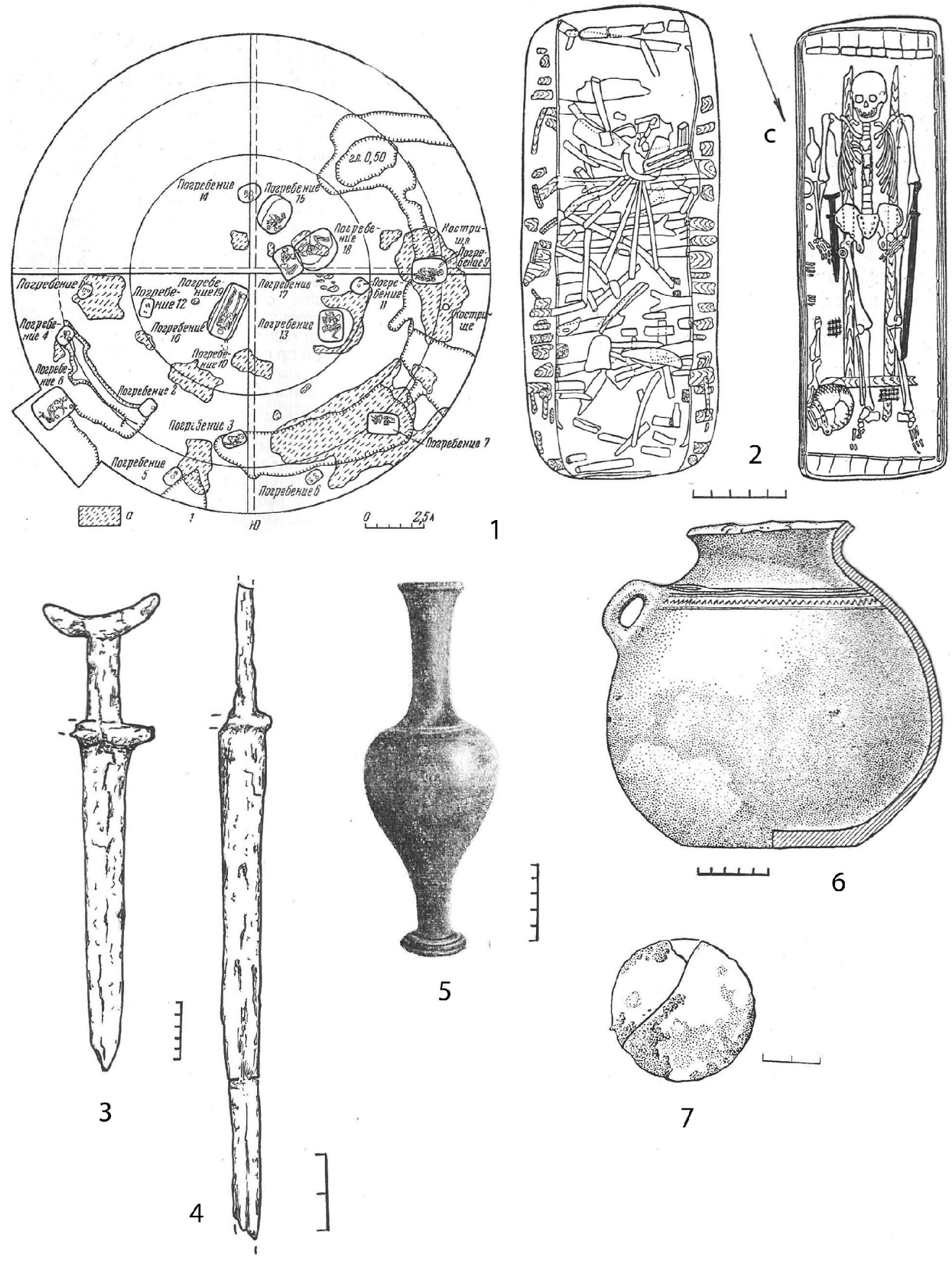

3

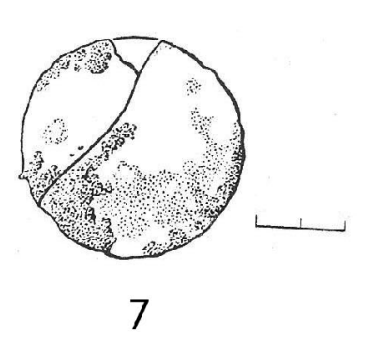

Рис. 4. Политотдельское, курган 12, погребение 19:

1 - план кургана; 2 - погребение 19; 3 - железный кинжал; 4 - железный меч; 5 - угвентарий; 6 - глиняный кувшин; 7 - бронзовое зеркало

Fig. 4. Politotdelskoe, barrow 12, burial 19:

1 - plan of the barrow; 2 - burial 19; 3 - iron dagger; 4 - iron sword; 5 - unguentarium; 6 - clay jar; 7 - bronze mirror 


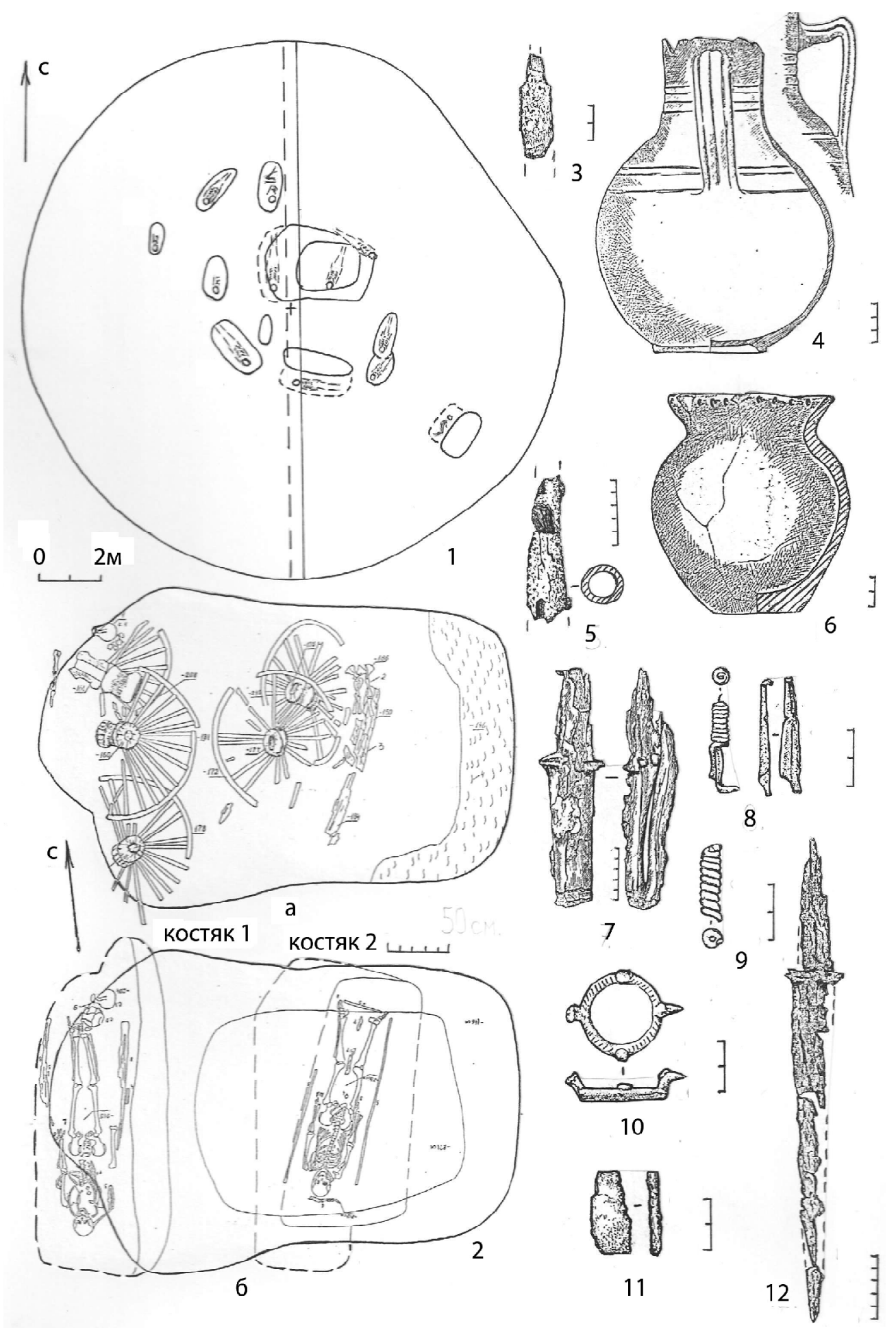

Рис. 5. Политотдельское, курган 4, погребение 13 (3-9-инвентарь костяка 1, 10-12 - инвентарь костяка 2): 1 - план кургана; 2 - погребение 13 ( $a$ - заклад подбоев; $\sigma$ - захоронения в подбоях); 3 - фрагмент железного ножа; 4 - глиняный кувшин; 5 - втулка железного копья; 6 - глиняный горшок; 7 - железный меч, согнутый пополам; 8 - фрагменты бронзовой фибулы; 9 - бронзовая пронизь; 10 - бронзовая пряжка; 11 - обломок железного ножа; 12 - железный меч

Fig. 5. Politotdelskoe, barrow 4, burial 13 (3-9-skeleton's inventory 1, 10-12-skeleton's inventory 2):

1 - plan of the barrow; 2 - burial 13 ( $a$ - backfill of kerves; $b$ - burials in kerves); 3 - fragment of iron knife; 4 - clay jar; 5 - hub of iron spear; 6 - clay pot; 7 - iron sword, bent in half; 8 - fragments of bronze fibulae; 9 - bronze string of beads; 10 - bronze buckle; 11 - fragment of iron knife; 12 - iron sword 


\section{АРХЕОЛОГИЯ}

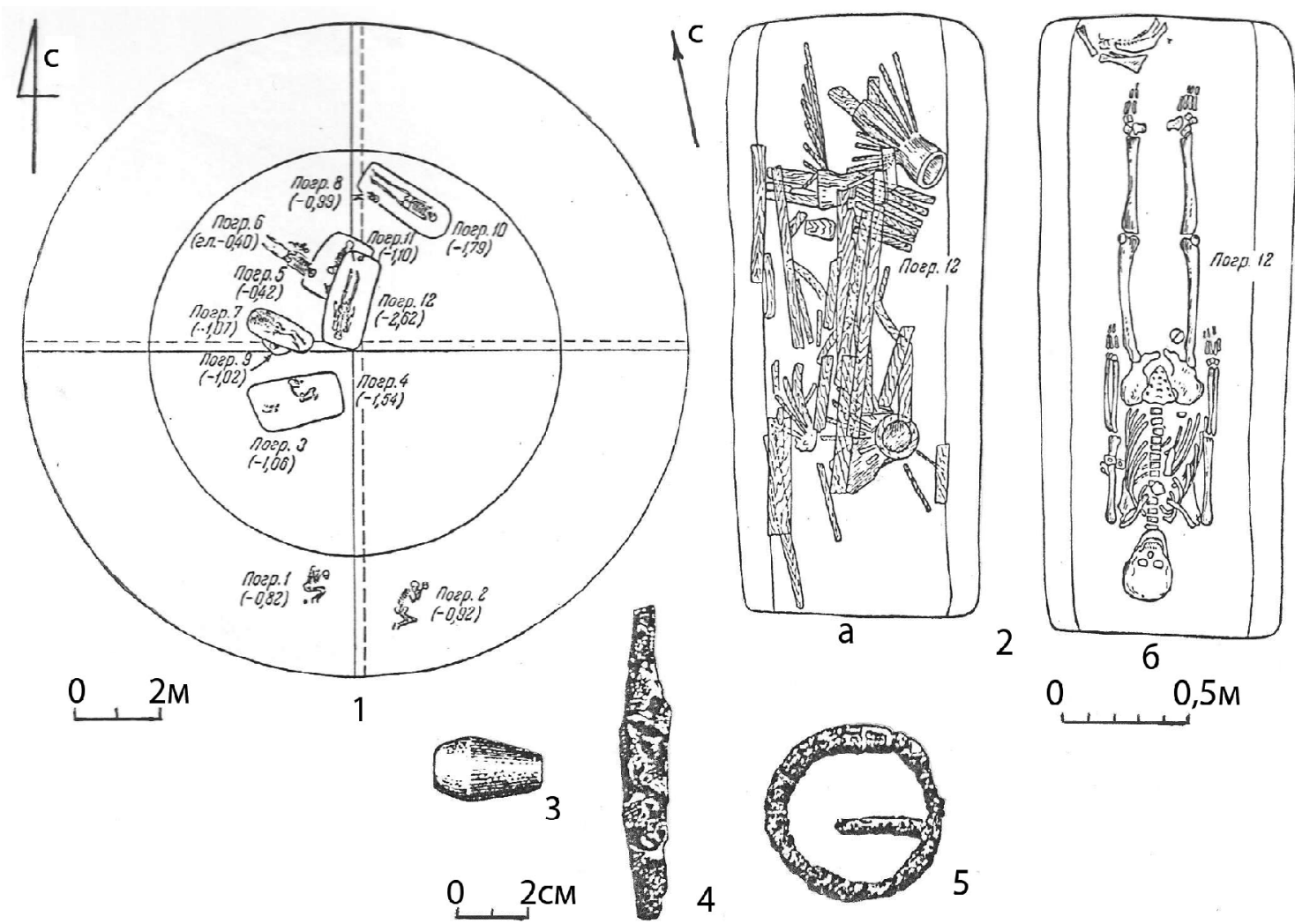

Рис. 6. Быково I, курган 17, погребение 12:

1 - план кургана; 2 - погребение 12 ( $а$ - заклад; 6 - погребение); 3 - каменная пронизь; 4 - железный нож; 5 - железная пряжка

Fig. 6. Bykovo I, barrow 17, burial 12:

1 - plan of the barrow; 2 - burial 12 ( $a$ - backfill; $b$ - burial); 3 - stone string of beads; 4 - iron knife; 5 - iron buckle 
B.M. Клепиков. Погребения раннесарматской культуры Нижнего Поволжья с деталями повозки

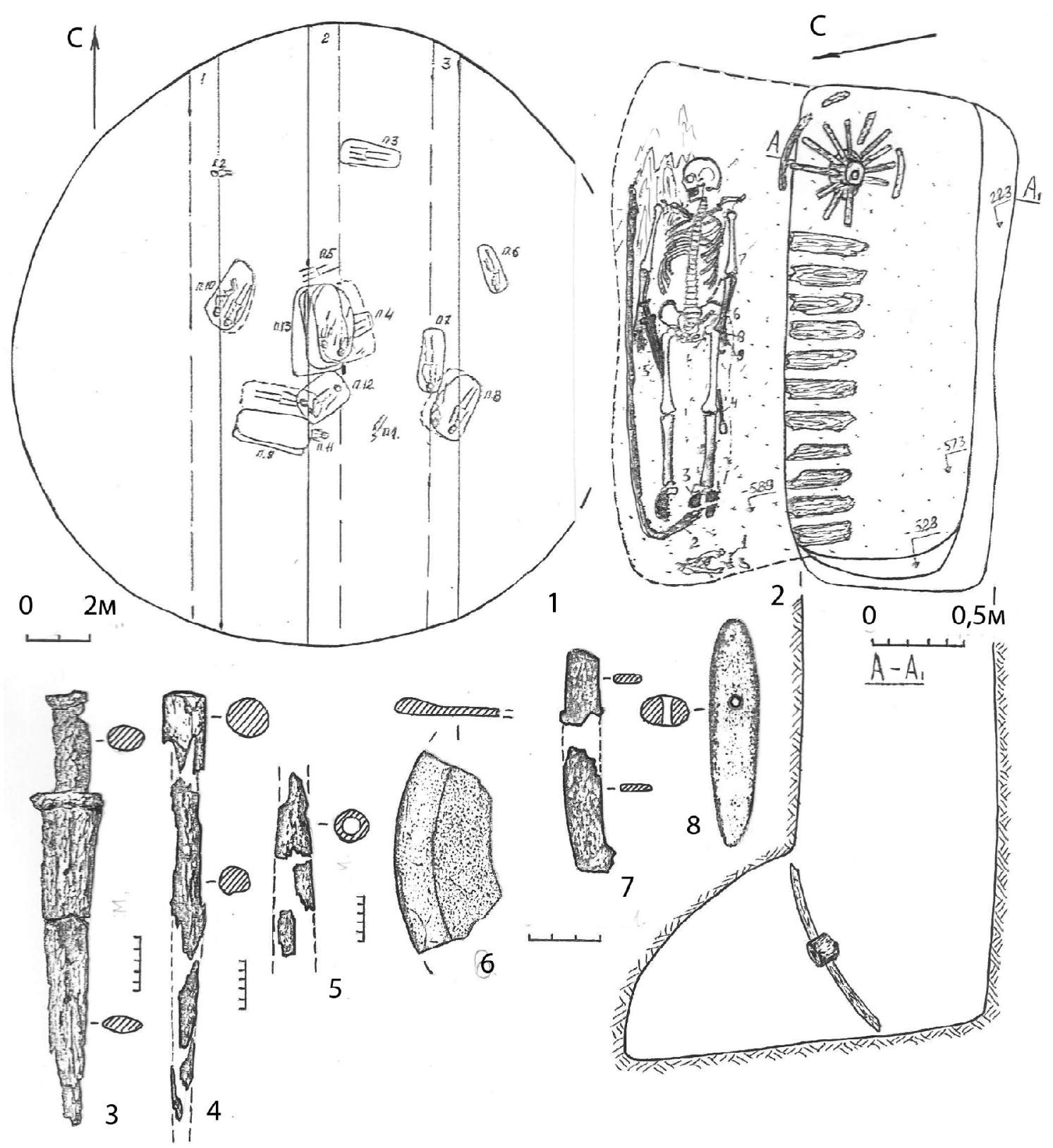

Рис. 7. Солодовка I, курган 4, погребение 9:

1 - план кургана; 2 - погребение 9 (план и разрез); 3 - железный кинжал;

4 - железный предмет с костяным навершием; 5 - фрагменты втулки железного копья; 6 - обломок бронзового зеркала; 7 - железный нож; 8 - оселок

Fig. 7. Solodovka I, barrow 4, burial 9:

1 - plan of the barrow; 2 - burial 9 (plan and sectional drawing); 3 - iron dagger;

4 - iron item with bone surface; 5 - hubs of iron spear;

6 - fragment of bronze mirror; 7 - iron knife; 8 - whet stone 


\section{АРХЕОЛОГИЯ}

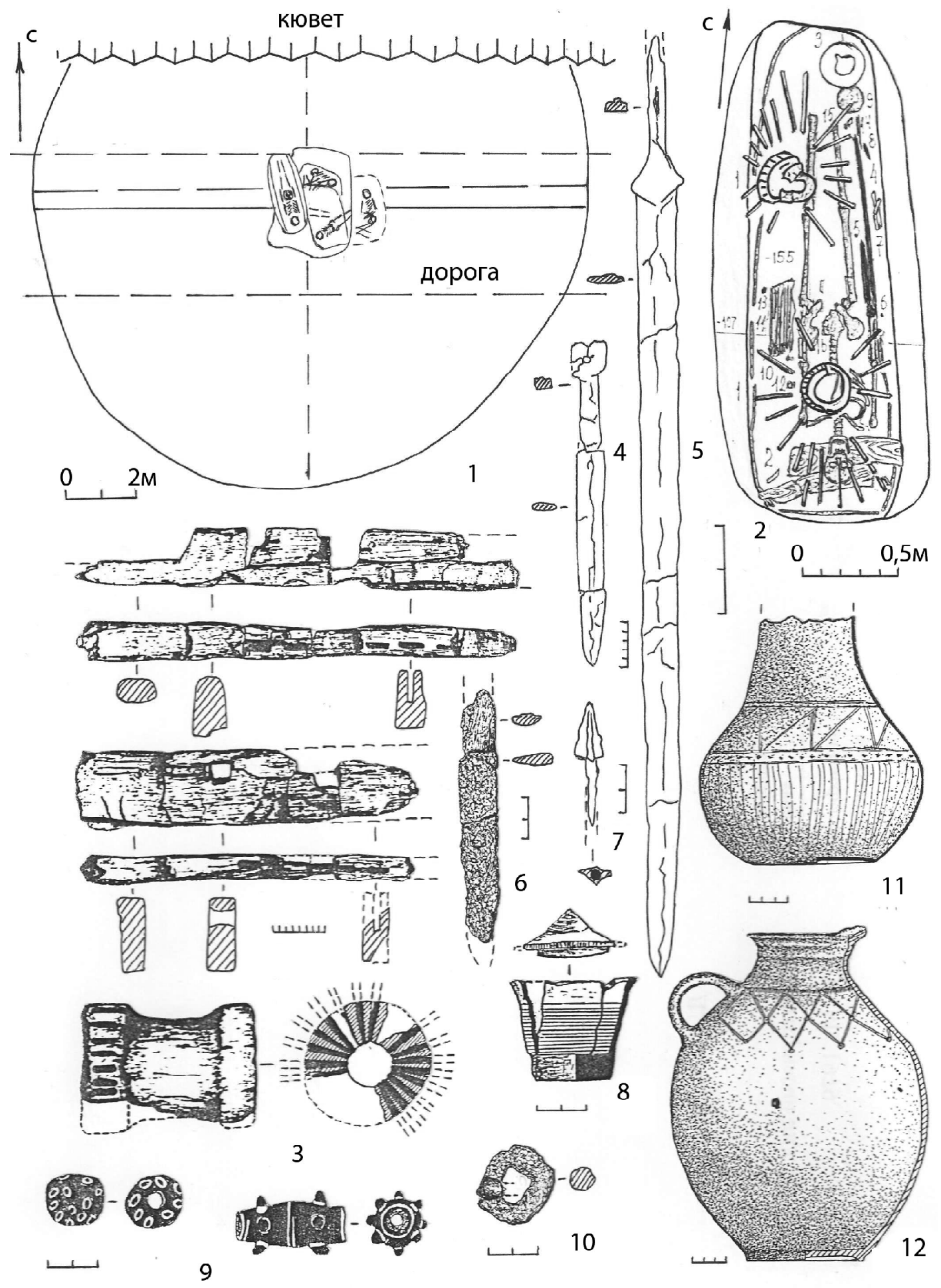

Рис. 8. Антонов, курган 3, погребение 3:

1 - план кургана; 2 - погребение 3; 3 - детали повозки; 4 - железный кинжал; 5 - железный меч;

6 - железный нож; 7 - железные наконечники стрел; 8 - деревянная пискида; 9 - бусы; 10 - железное кольцо; 11 - глиняный сосуд; 12 - глиняный кувшин

Fig. 8. Antonov, barrow 3, burial 3:

1 - plan of the barrow; 2 - burial 3; 3 - details of cart; 4 - iron dagger; 5 - iron sword; 6 - iron knife; 7 - iron arrowheads; 8 - wooden pyxis; 9 - beads; 10 - iron ring;

11 - clay vessel; 12 - clay jar 
В.М. Клепиков. Погребения раннесарматской культуры Нижнего Поволжья с деталями повозки

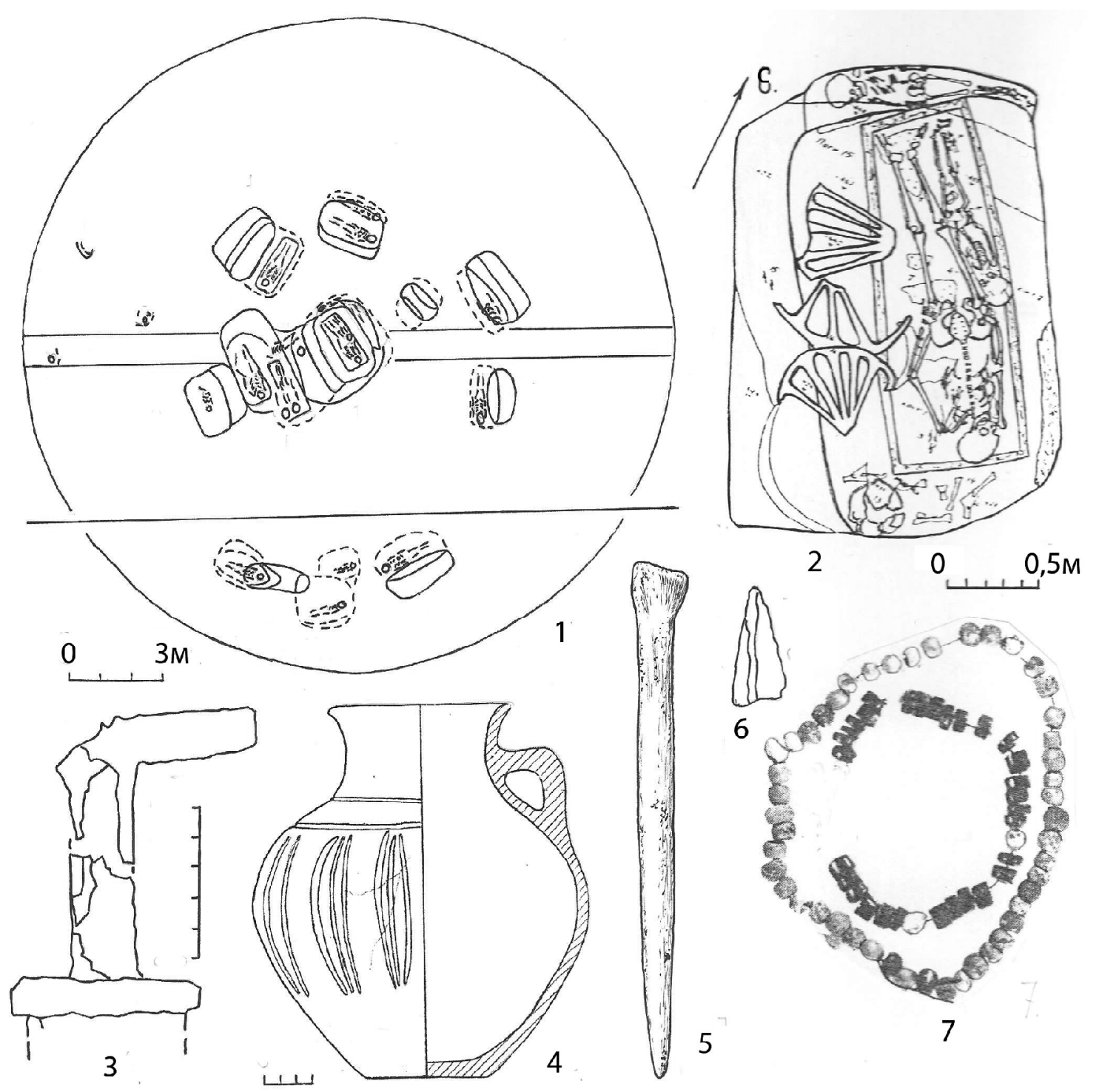

Рис. 9. Кривая Лука VIII, курган 5, погребение 15:

1 - план кургана; 2 - погребение 15; 3 - фрагмент железного кинжала; 4 - глиняный кувшин; 5 - костяная проколка; 6 - бронзовый наконечник стрелы; 7 - бусы

Fig. 9. Krivaya Luka VIII, barrow 5, burial 15:

1 - plan of the barrow; 2 - burial 15; 3 - iron dagger; 4 - clay jar;

5 - bone piercing; 6 - bronze arrowhead; 7 - beads 


\section{АРХЕОЛОГИЯ}

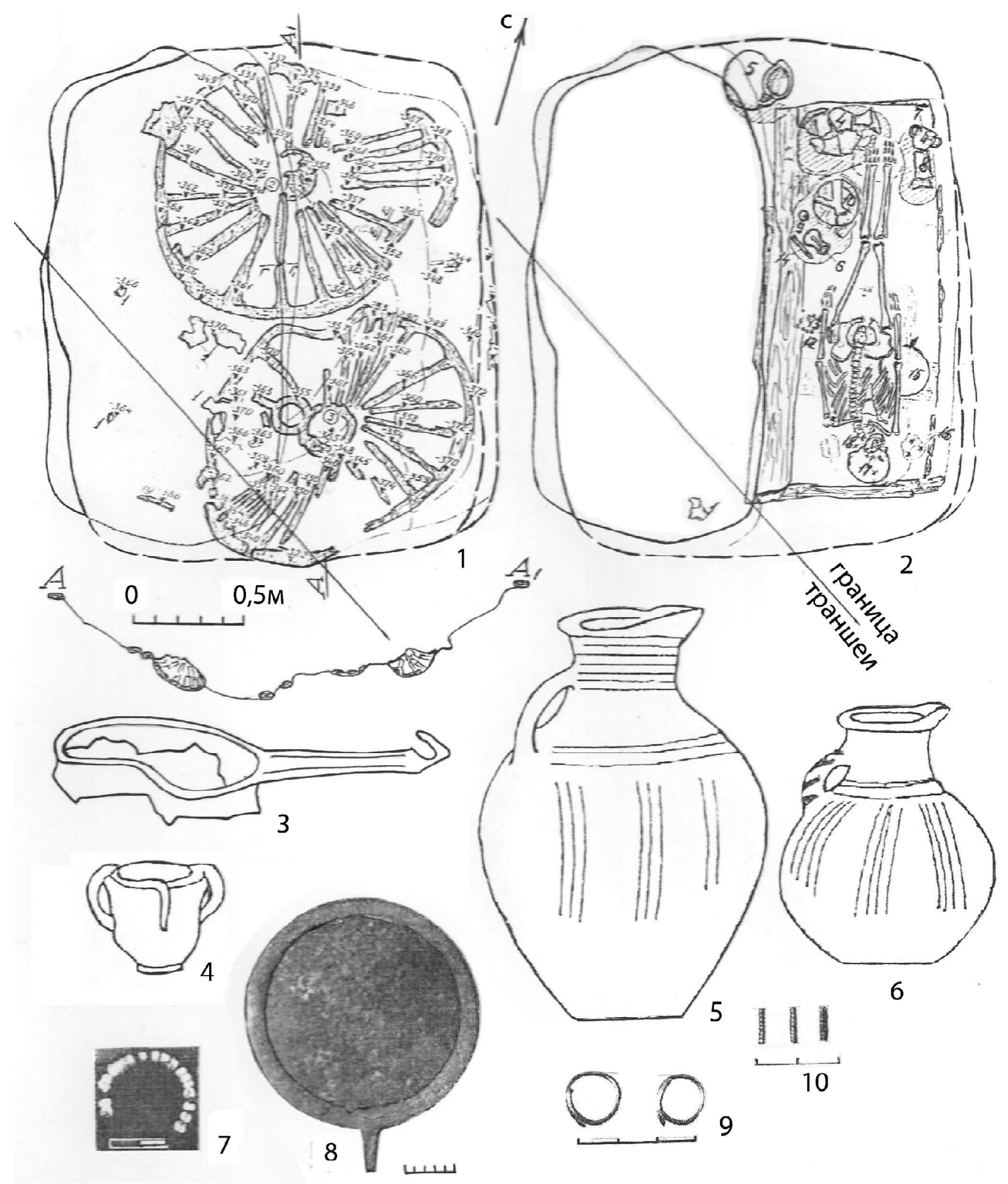

Рис. 10. Косика I, погребение 2:

1 - заклад входной ямы; 2 - погребение $2 ; 3$ - бронзовая сковородка; 4 - трехручный канфар;

5-6 - глиняные кувшины; 7 - бусы; 8 - бронзовое зеркало; 9 - золотые серьги; 10 - золотые пронизи

Fig. 10. Kosika I, burial 2:

1 - backfill of enter pit; 2 - burial 2; 3 - bronze pan; 4 - three-lever cantharos;

5 -6 - clay jars; 7 - beads; 8 - bronze mirror; 9 - golden earrings; 10 - golden strings of beads 


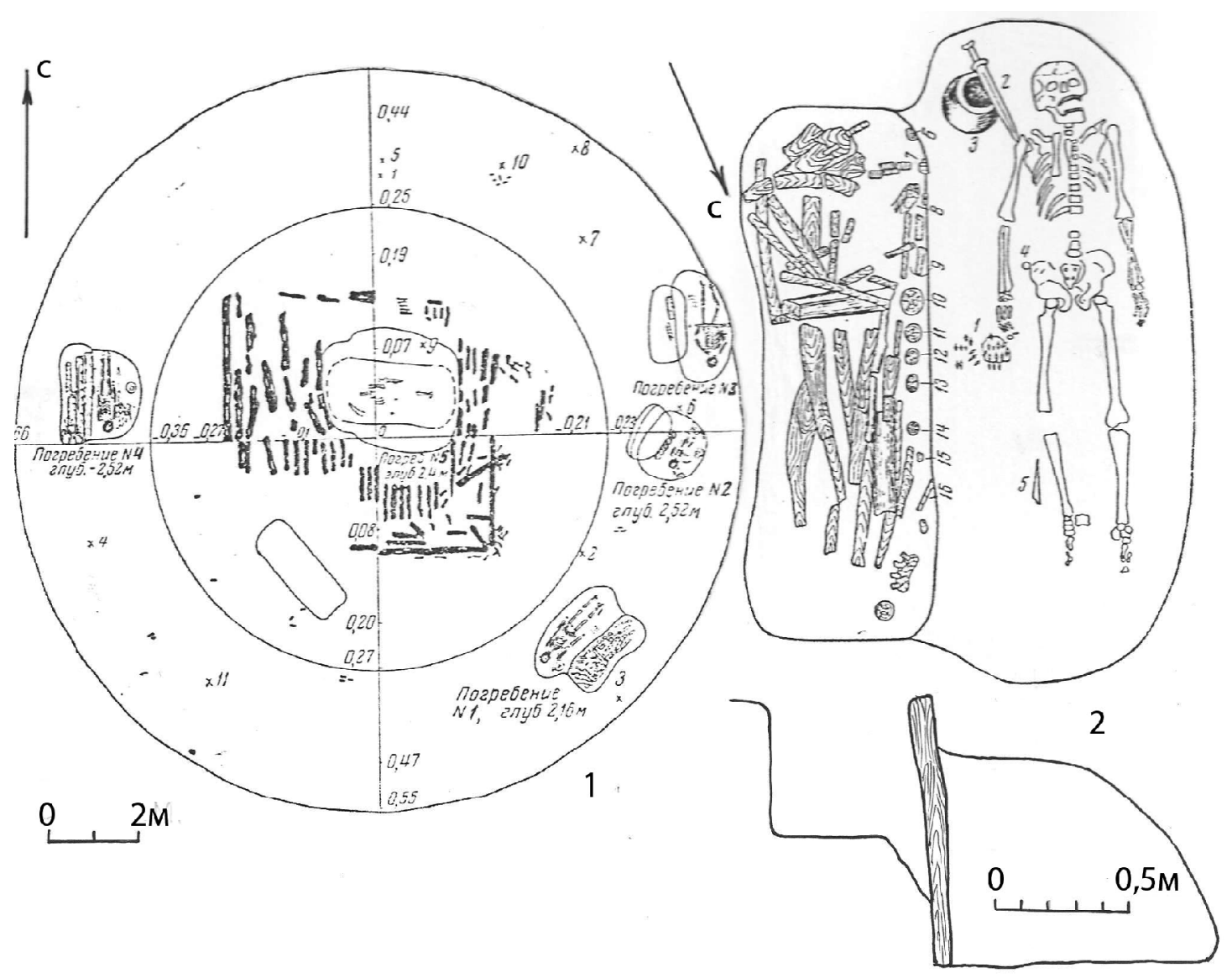

Рис. 11. Лапасина, курган 1, погребение 1:

1 - план кургана; 2 - погребение 1 (план и разрез)

Fig. 11. Lapasina, barrow 1, burial 1:

1 - plan of the barrow; 2 - burial 1 (pland and section drawing)

\section{СПИСОК ЛИТЕРАТУРЫ}

1. Балонов, Ф. Р. Колесный транспорт сарматской эпохи / Ф. Р. Балонов // Археология Южной Сибири. - Кемерово : Изд-во Кемер. гос. ун-та, 1980. - C. 69-85.

2. Комаров, А. М. Отчет о раскопках курганных могильников у с. Политотдельское (Николаевский район), Хохлачевский (Среднеахтубинский район), у хутора Молокановский (Октябрьский район), Казачий (Котельниковский район) и одиночного кургана у с. Песковатка (Калачевский район) в зонах строительства оросительных систем в Волгоградской области в 1989 г. / А. М. Комаров, О.В.Кузьмина, А. Ю. Иванов // Архив ВОКМ. 1990. - Ф. 102.

3. Кропотов, В. В. Фибулы сарматской эпохи / В. В. Кропотов. - Киев : АДЕФ-Украина, 2010. - 384 с.

4. Мамонтов, В. И. Курганный могильник Антонов I / В. И. Мамонтов // Древности Волго-Донских степей. - Волгоград : Перемена, 1994. - С. 15-46.
5. Марченко, И. И. Сираки Прикубанья / И. И. Марченко. - Краснодар : Изд-во Кубан. гос. ун-та, 1996. - 337 с.

6. Мыськов, Е. П. Отчет о работе Волго-Ахтубинского отряда археологической экспедиции Волгоградского пединститута в 1991 году / Е. П. Мыськов // Архив ВОКМ. - 1991.-Ф. 80.

7. Раев, Б. А. Азиатские элементы обряда захоронения у с. Косика (Косика-2) / Б. А. Раев, В. В. Дворниченко // Материалы IV Международной научной конференции «Кадырбаевские чтения - 2014». - Актобе ; Астана : Мега принт, 2014. - C. 170-174.

8. Синицын, И. В. Археологические раскопки на территории Нижнего Поволжья / И. В. Синицын. - Саратов : Изд-во СГУ, 1947. - 134 с.

9. Скрипкин, А. С. Хронология раннесарматской культуры Нижнего Поволжья / А. С. Скрипкин, В. М. Клепиков // Сарматские культуры Евразии: проблемы региональной хронологии. - Краснодар : [б. и.], 2004. - С. 95-106. 
10. Смирнов, К. Ф. Быковские курганы / К. Ф. Смирнов // Древности Нижнего Поволжья. МИА.-М. : Изд-во АНСССР, 1960.-№ 78.-С. 169-272.

11. Смирнов, К. Ф. Курганы у сел Иловатка и Политотдельское Сталинградской области / К. Ф. Смирнов // Древности Нижнего Поволжья. МИА. - М. : Изд-во АНСССР, 1959. - №60. - С. 206-322.

12. Смирнов, К. Ф. Новые сарматские памятники на Бузулуке / К. Ф. Смирнов // КСИА. - М., 1962. - Вып. 89. - С. 83-93.

13. Федоров-Давыдов, Г. А. Отчет о раскопках курганов в урочище «Кривая Лука» в Черноярском районе Астраханской области в 1974 г. / Г. А. Федоров-Давыдов, В. В. Дворниченко, Н. В. Малиновская // Архив ИА РАН. - 1975. - Р-1. - № 5315.

\section{REFERENCES}

1. Balonov F.R. Kolesnyy transport sarmatskoy epokhi [Wheel Transport of the Sarmatian Era]. Arkheologiya Yuzhnoy Sibiri [The Archaeology of Southern Siberia]. Kemerovo, Izd-vo Kemer. GU, 1980, pp. 69-85.

2. Komarov M.A., Kuzmina O.V., Ivanov A.Yu. Otchet o raskopkakh kurgannykh mogilnikov u s. Politotdelskoe (Nikolaevskiy rayon), Khokhlachevskiy (Sredneakhtubinskiy rayon), $u$ khutora Molokanovskiy (Oktyabrskiy rayon), Kazachiy (Kotelnikovskiy rayon) $i$ odinochnogo kurgana u s. Peskovatka (Kalachevskiy rayon) $v$ zonakh stroitelstva orositelnykh sistem $v$ Volgogradskoy oblasti v $1989 \mathrm{~g}$. [Report on the Excavations of Burial Grounds near Politotdelskoe Village (the Nikolaevsky District), Khokhlachevskiy (Sredneakhtubinskiy District), near the Molokanovskiy Farm of(Oktyabrskiy District), Cossacks' (Kotelnikovo District) and a Single Barrow near Peskovatka Village (Kalachevskiy District) in the Areas of Irrigation Systems Construction in the Volgograd Region in 1989]. Arkhiv VOKM, 1990, F. 102.

3. Kropotov V.V. Fibuly sarmatskoy epokhi [Fibulae of the Sarmatian Era]. Kiev, ADEF-Ukraina Publ., 2010. 384 p.

4. Mamontov V.I. Kurgannyy mogilnik Antonov I [Antonov I Burial Ground]. Drevnosti Volgo-Donskikh stepey [Antiquities of the Volga-Don Steppes]. Volgograd, Peremena Publ., 1994, pp. 15-46.

5. Marchenko I.I. Siraki Prikubanya [The Siraks of the Kuban Region]. Krasnodar, Izd-vo Kuban. GU, 1996. 337 p.
6. Myskov E.P. Otchet o rabote VolgoAkhtubinskogo otryada arkheologicheskoy ekspeditsii Volgogradskogo pedinstituta v 1991 godu [Report on the Work of the Volga-Akhtuba Detachment of Archaeological Expedition of the Volgograd Pedagogical Institute in 1991]. Arkhiv VOKM, 1991, F. 80.

7. Raev B.A., Dvornichenko V.V. Aziatskie elementy obryada zakhoroneniya u s. Kosika (Kosika2) [Asian Elements of the Burial Rite near Kosika Village (Kosika-2)]. Materialy IV Mezhdunarodnoy nauchnoy konferentsii «Kadyrbaevskie chteniya - 2014» [Proceedings of the $4^{\text {th }}$ International Academic Conference "Kadyrbaev's Readings - 2014"]. Aktobe; Astana, Mega print Publ., 2014, pp. 170-174.

8. Sinitsyn I.V. Arkheologicheskie raskopki na territorii Nizhnego Povolzhya [Archaeological Excavations on the Territory of the Lower Volga Region]. Saratov, Izd-vo SGU, 1947. 134 p.

9. Skripkin A.S., Klepikov V.M. Khronologiya rannesarmatskoy kultury Nizhnego Povolzhya [Chronology of the Early Sarmatian Culture of the Lower Volga Region]. Sarmatskie kultury Evrazii: problemy regionalnoy khronologii [Sarmatian Culture of Eurasia: Problems of Regional Chronology]. Krasnodar, 2004, pp. 95-106.

10. Smirnov K.F. Bykovskie kurgany [Bykovsky Mounds]. Drevnosti Nizhnego Povolzhya. MIA [Antiquities of the Lower Volga Region. Materials and Investigations on Archaeology of the USSR]. Moscow, Izd-vo AN SSSR, 1960, no. 78, pp. 169-272.

11. Smirnov K.F. Kurgany u sel Ilovatka i Politotdelskoe Stalingradskoy oblasti [Barrows near Ilovatka and Politotdelskoe Villages of the Stalingrad Region]. Drevnosti Nizhnego Povolzhya. MIA [Antiquities of the Lower Volga Region. Materials and Investigations on Archaeology of the USSR]. Moscow, Izd-vo AN SSSR, 1959, no. 60, pp. 206-322.

12. Smirnov K.F. Novye sarmatskie pamyatniki na Buzuluke [New Sarmatian Monuments in Buzuluk]. Kratkie soobshcheniya Instituta arkheologii, 1962, iss. 89, pp. 83-93.

13. Fedorov-Davydov G.A., Dvornichenko V. V., Malinovskaya N.V. Otchet o raskopkakh kurganov v urochishche "Krivaya Luka" v Chernoyarskom rayone Astrakhanskoy oblasti v 1974 g. [Report on the Excavations of Burial Mounds in the Krivaya Luka Area in the Chernoyarsky District of the Astrakhan Region in 1974]. Arkhiv IA $R A N$, 1975, R-1, no. 5315. 
B.M. Клепиков. Погребения раннесарматской культуры Нижнего Поволжья с деталями повозки

\section{Information About the Author}

Valeriy M. Klepikov, Candidate of Sciences (History), Associate Professor, Department of Archaeology, Foreign History and Tourism, Volgograd State University, Prosp. Universitetsky, 100, 400062 Volgograd, Russian Federation, valery.klepikov@volsu.ru, adsi@volsu.ru, http://orcid.org/00000003-2891-7366

\section{Информация об авторе}

Валерий Михайлович Клепиков, кандидат исторических наук, доцент кафедры археологии, зарубежной истории и туризма, Волгоградский государственный университет, просп. Университетский, 100, 400062 г. Волгоград, Российская Федерация, valery.klepikov@volsu.ru, adsi@volsu.ru, http://orcid.org/0000-0003-2891-7366 